\title{
Does genome size in Dasypyrum villosum vary with fruit colour?
}

\author{
R Obermayer and J Greilhuber \\ Department of Systematic and Evolutionary Botany, University of Vienna, Rennweg 14, A-1030 Vienna, Austria
}

\begin{abstract}
Dasypyrum villosum $(2 n=14)$, a Mediterranean grass species of the Triticeae, exhibits intraindividual fruit colour polymorphism from pale yellow to almost black. Several studies have reported differences between the plants emerging from pale and dark fruits. They include histone content in root meristem nuclei, cell cycle duration, heterochromatin banding pattern, frequency of a tandemly repeated sequence, and nuclear genome size. In the present study, we examine whether the reports of genome size being up to 1.24-fold larger in seedlings from the lighter caryopses are reproducible. In all, 29 accessions from various countries, totaling 186 plants, were investigated for genome size using flow cytometry with propidium iodide as the DNA stain.
\end{abstract}

Individuals differed 1.12-fold at most and accessions 1.07fold. The mean genome size (1C-value) was $5.07 \mathrm{pg}$ or $4954 \mathrm{Mbp}$. Within-accession comparisons of seedlings derived from light and dark caryopses were insignificant $(P>0.100)$. Thus, we found no evidence for a modificatory genome size plasticity in $D$. villosum. In the light of our data, the previously reported genome size variation, up to 1.66-fold within populations and 1.67-fold between populations, appears unrealistically high. Suboptimal technical procedures for quantitative Feulgen staining are probably responsible for these earlier observations.

Heredity (2005) 95, 91-95. doi:10.1038/sj.hdy.6800696

Published online 25 May 2005

Keywords: Dasypyrum villosum; genome size; flow cytometry; Feulgen densitometry; plastic genome; Triticeae

\section{Introduction}

The analysis of genome size variation has been a multifaceted problem since the early days of cytophotometry, involving instrumentation, preparation, materialdependent, and taxonomic issues (Bennett and Smith, 1976; Greilhuber, 1998). The methods that are currently widely used to estimate genome size are flow cytometry of isolated nuclei (with DNA stained using baseindifferent fluorochromes such as propidium iodide) and Feulgen densitometry. The two approaches give comparable results (Doležel et al, 1998; Vilhar et al, 2001). Although in principle not complicated or difficult to conduct, these methods have resulted in a wealth of observations in plants over the decades that are hard to understand or to accept, and which have been aptly categorized under the headings 'plastic' or 'fluid' genome and 'unorthodox' genome size variation (Greilhuber, 1998). These terms refer to rapid and conspicuous changes in the basic quantity of nuclear DNA (C-values), that is, the amount found in mitotic nuclei or in the G1 nuclei of vital tissues. The changes might be developmentally triggered or a response to exogenous stimuli. Bennett and Leitch (1995, 2005a) and Greilhuber (1998) have provided topical reviews and discussion.

Here, we address a purported plastic genome phenomenon in Dasypyrum villosum (Cremonini et al, 1994; Frediani et al, 1994). This annual diploid Mediterranean

Correspondence: $R$ Obermayer, Department of Systematic and Evolutionary Botany, University of Vienna, Rennweg 14, A-1030 Vienna, Austria.E-mail: renate.obermayer@univie.ac.at

Received 12 November 2004; accepted 21 March 2005; published online 25 May 2005 grass species exhibits an intraindividual fruit colour polymorphism from yellow (pale) over medium brown to almost black (dark), the fruit size being larger in pale fruits than in darker ones. Similar polymorphism is seen in some other wild Triticeae.

Previous authors have discriminated two classes of fruit colour only, and found that dark fruits differed from pale ones: in longer dormancy and better germination rate at higher temperature (Onnis, 1967), higher and longer-lasting ascorbic acid peroxidase content (De Gara et al, 1991), almost constant histone/DNA ratio in embryo root meristem over time, in contrast to an increasing ratio in pale fruits (Innocenti and Bitonti, 1980), shorter mitotic cycles (Innocenti and Bitonti, 1983), some differences in heterochromatin (Cremonini et al, 1994), and lower genome size (as measured in root tip nuclei with the Feulgen method; Cremonini et al, 1994; Frediani et al, 1994; Cremonini, 1996). Cremonini et al (1994) found a 1.20-1.24-fold larger genome size in seedling root tips from pale fruits. Frediani et al (1994) studied the modulation of genome size and of a repeated $396 \mathrm{bp}$ sequence during germination in material from seven distant populations in Italy. Their complex results may be summarized as follows: population mean genome size (as measured from dry seeds) differs up to 1.67-fold. Seedlings from yellow caryopses have on average 1.14-fold larger genomes, although plants of the same caryopsis colour group and the same population can differ 1.15-fold. During germination and further plant development, there are fluctuations in genome size, after which it reaches the levels of dry embryos again.

Our aim was to obtain an independent data set from $D$. villosum for which the extent of genome size variation and its relationship with fruit colour could be evaluated. 


\section{Materials and methods}

A total of 29 accessions of D. villosum (L.) P. Candargy $(2 n=14)$ from several countries in the Mediterranean area were obtained from the IPK (Institut für Pflanzengenetik und Kulturpflanzenforschung), Gatersleben (Table 1). Caryopses of each accession were classified according to their colour, which varied, apparently continuously, from yellow (pale) to almost black (dark). Within this continuum, three classes were established, that is, pale, medium, and dark. From these fruits plants were grown in a glasshouse, so that of any accession three (or exceptionally six) plants per available fruit colour were obtained. From one to three colour classes were found in each accession, resulting in samples of three, six, or nine plants. Pisum satioum 'Kleine Rheinländerin' ( $2 C=8.84$ pg; Greilhuber and Ebert, 1994) was grown under glass to provide material for use as an internal standard in the measurement of genome size by flow cytometry. This species was also germinated on plates as a standard for Feulgen DNA image densitometry. Herbarium specimens were made from most of these accessions and are kept in WU.

Flow cytometry was conducted as described in Obermayer and Greilhuber (1999). In short, for isolation of nuclei, leaf material from young $D$. villosum plants and from $P$. sativum 'Kleine Rheinländerin' was chopped together in isolation buffer, sieved, the isolate treated with RNase and stained with propidium iodide. Fluorescence emission of nuclei was detected on a Partec PA II flow cytometer. Instrument linearity and optical adjustment were controlled using chicken red blood cells. One preparation and three runs were carried out on each $D$. villosum plant, and at least 5000 nuclei were measured per run. As a quality criterion, a coefficient of variation of G1 peaks better than 3\% was determined.

For Feulgen DNA image densitometry on the CIRES (release 3.1; Kontron, Munich; cf. Vilhar et al, 2001), root tips from germinated seedlings of the $D$. villosum accessions no. 10 and 21 with very high differences in DNA content were cofixed in $4 \%$ formaldehyde. DNA content of telophase and prophase nuclei was measured (for the staining method, see Greilhuber and Ebert, 1994). These preparations were also used for chromosome counting, which confirmed a karyotype of $2 n=14$.

Statistical tests (the paired $t$-test, simple and hierarchical ANOVA, and Scheffé-test) were conducted using the programs Excel, SPSS, and BIOM.

\section{Results}

In total 186 individuals from 29 accessions were measured for genome size by flow cytometry (Table 1). Based on a $4.42 \mathrm{pg}(1 C)$ value for the P. sativum standard, the genome size of $D$. villosum was on average 5.065 pg or $4953.6 \mathrm{Mbp}$ (1C) (using the conversion factor $1 \mathrm{pg}=978 \mathrm{Mbp}$; see Doležel et al, 2003). Individual plants differed up to 1.119-fold, and accession means differed 1.075 -fold (4.92-5.29 pg or $4811.8-5173.6 \mathrm{Mbp}, 1 C)$. These differences were significant $(P<0.001)$ when assessed

Table 1 C-values in Dasypyrum villosum

\begin{tabular}{|c|c|c|c|c|c|c|c|}
\hline Acc. no. & IPK nо. & $\mathrm{N}$ & Ratio & $S D$ & $1 C(p g)$ & $1 C(\mathrm{Mbp})$ & Scheffé group \\
\hline 1 & GRA $891 / 80$ & 6 & 1.138 & 0.0144 & 5.029 & 4918.4 & $1,2,3$ \\
\hline 2 & GRA $895 / 80$ & 3 & 1.134 & 0.0067 & 5.012 & 4901.7 & 1,2 \\
\hline 3 & GRA $892 / 80$ & 3 & 1.148 & 0.0146 & 5.074 & 4962.4 & $1,2,3$ \\
\hline 4 & GRA 896/80 & 6 & 1.140 & 0.0102 & 5.038 & 4927.2 & $1,2,3$ \\
\hline 5 & GRA 910/81 & 6 & 1.136 & 0.0196 & 5.021 & 4910.5 & 1,2 \\
\hline 6 & GRA $955 / 83$ & 6 & 1.144 & 0.0199 & 5.056 & 4944.8 & $1,2,3$ \\
\hline 7 & HGRA $960 / 83$ & 6 & 1.133 & 0.0164 & 5.007 & 4896.9 & 1,2 \\
\hline 8 & GRA 961/83 & 6 & 1.142 & 0.0158 & 5.047 & 4936.0 & $1,2,3$ \\
\hline 9 & GRA $962 / 83$ & 6 & 1.150 & 0.0110 & 5.083 & 4971.2 & $1,2,3$ \\
\hline 10 & GRA 992/88 & 9 & 1.184 & 0.0230 & 5.233 & 5117.9 & 2,3 \\
\hline 11 & GRA $1020 / 86$ & 3 & 1.151 & 0.0113 & 5.087 & 4975.1 & $1,2,3$ \\
\hline 12 & GRA $1022 / 86$ & 9 & 1.147 & 0.0289 & 5.065 & 4953.6 & $1,2,3$ \\
\hline 13 & GRA 1027/88 & 6 & 1.154 & 0.0140 & 5.100 & 4987.8 & $1,2,3$ \\
\hline 14 & GRA 1105/91 & 9 & 1.132 & 0.0103 & 5.003 & 4892.9 & 1,2 \\
\hline 15 & GRA $1106 / 87$ & 9 & 1.164 & 0.0094 & 5.144 & 5030.8 & $1,2,3$ \\
\hline 16 & GRA 1109/87 & 6 & 1.146 & 0.0084 & 5.065 & 4953.6 & $1,2,3$ \\
\hline 17 & GRA 1113/87 & 6 & 1.155 & 0.0088 & 5.105 & 4992.7 & $1,2,3$ \\
\hline 18 & GRA $1114 / 87$ & 6 & 1.173 & 0.0182 & 5.184 & 5070.0 & $1,2,3$ \\
\hline 19 & GRA 1164/88 & 3 & 1.156 & 0.0061 & 5.109 & 4996.6 & $1,2,3$ \\
\hline 20 & GRA $1170 / 90$ & 6 & 1.131 & 0.0098 & 4.999 & 4889.0 & 1,2 \\
\hline 21 & GRA $1305 / 91$ & 6 & 1.113 & 0.0088 & 4.919 & 4810.8 & 1 \\
\hline 22 & GRA 1310/91 & 6 & 1.119 & 0.0062 & 4.945 & 4836.2 & 1 \\
\hline 23 & GRA 1313/91 & 9 & 1.116 & 0.0089 & 4.932 & 4823.5 & 1 \\
\hline 24 & GRA 2262/92 & 6 & 1.136 & 0.0112 & 5.021 & 4910.5 & 1,2 \\
\hline 25 & GRA 2628/95 & 6 & 1.148 & 0.0157 & 5.074 & 4962.4 & $1,2,3$ \\
\hline 26 & GRA 2630/95 & 9 & 1.182 & 0.0265 & 5.224 & 5109.1 & 2,3 \\
\hline 27 & GRA 2706/97 & 6 & 1.133 & 0.0104 & 5.007 & 4896.9 & 1,2 \\
\hline 28 & GRA $2707 / 98$ & 9 & 1.132 & 0.0013 & 5.003 & 4892.9 & 1,2 \\
\hline 29 & GRA $2713 / 98$ & 9 & 1.197 & 0.0085 & 5.290 & 5173.6 & 3 \\
\hline Mean & & & 1.146 & & 5.065 & 4953.6 & \\
\hline
\end{tabular}

List of accessions, with identification number of the IPK germplasm collection (IPK no.), number of individuals measured ( $N$ ), relative genome size presented as channel number ratio vs Pisum sativum (ratio) with standard deviation (SD) between means of individuals, $1 C$-value in $\mathrm{pg}$ and $\mathrm{Mbp}$, and Scheffé group at $P<0.05$. 
using simple and hierarchical ANOVA. A geographical pattern of genome size distribution was not evident. The accessions could be divided into at least three homogeneous Scheffé groups (Table 1): three accessions had very low size (group 1), one very high (group 3), and 25 intermediate (group 2).

As is often the case with seed bank material, the origin of the material was given only by country or as unknown. However, this does not impair our aim of assessing the presence or absence of differences between plants derived from differently coloured caryopses. Towards this goal, the accession means of each colour (pale, medium, and dark) or colour combination (medium plus dark and pale plus medium) were listed in a pairwise fashion, so that a paired two-sided $t$-test could be carried out. Of special importance in this regard is the comparison between plants from light and dark fruits, because this should reveal any differences in genome size most clearly (Table 2). This test was nonsignificant $(N=17, P=0.2124)$, and the mean of the ratio of pale $v s$ dark was only 1.0048. All other comparisons were also nonsignificant: pale $v$ s medium $(N=15 ; P=0.1445$; mean of ratios 0.9942$)$, medium vs dark $(N=6 ; P=0.2616$; mean of ratios 1.0137), pale vs medium plus dark $(N=6$; $P=0.4400$; mean of ratios 1.0081), and pale plus medium vs dark $(N=6 ; P=0.1054$; mean of ratios 1.0143$)$.

While accession means differed up to 1.075-fold, the genome sizes from differently coloured fruits within accessions were significantly $(P<0.001)$ correlated (Figure 1). This result indicates that the differences between accessions are probably more than pure methodological noise.

Table 2 Flow cytometric comparison in 17 accessions of Dasypyrum villosum seedlings grown from pale $(\mathrm{p})$ and dark (d) caryopses

\begin{tabular}{lccc}
\hline Acc. $n r$. & \multicolumn{2}{c}{ D. villosum/P. sativum ratios } & Ratio $p / d$ \\
\cline { 2 - 3 } & $p$ & $d$ & \\
\hline 23 & 1.113 & 1.118 & 0.9955 \\
7 & 1.119 & 1.148 & 0.9747 \\
14 & 1.121 & 1.143 & 0.9807 \\
22 & 1.121 & 1.118 & 1.0026 \\
27 & 1.132 & 1.133 & 0.9991 \\
8 & 1.134 & 1.150 & 0.9860 \\
20 & 1.134 & 1.129 & 1.0044 \\
28 & 1.140 & 1.117 & 1.0205 \\
12 & 1.142 & 1.117 & 1.0223 \\
24 & 1.144 & 1.128 & 1.0141 \\
5 & 1.150 & 1.122 & 1.0249 \\
9 & 1.158 & 1.142 & 1.0140 \\
15 & 1.169 & 1.161 & 1.0068 \\
18 & 1.172 & 1.173 & 0.9991 \\
26 & 1.183 & 1.160 & 1.0198 \\
10 & 1.187 & 1.160 & 1.0232 \\
29 & 1.193 & 1.199 & 0.9949 \\
& & & \\
Means & 1.148 & 1.142 & 1.0048 \\
Mean of ratios & & & 1.0049 \\
SD & & & 0.0153 \\
CV & & & 0.0153 \\
$N$ & & & \\
Paired $t$-test & $P=0.212$, NS & & \\
& & &
\end{tabular}

Accessions differed maximally 1.075-fold and significantly, while individuals from pale and dark fruits within accessions differed insignificantly upon two-sided paired $t$-test.
As another test for genuine variation, one individual each from two accessions differing strongly in DNA amount (no. 10 very high, no. 21 the lowest) and $P$. sativum as a standard were coprocessed. Two D. villosum peaks were found with a separation indicating a 1.12fold difference (Figure 2). This is compatible with the 1.09-fold difference found in these accessions between individuals and the extreme 1.12-fold overall difference between single seedlings (between accessions 26 and 23) as found in the other tests (data not shown, see Table 1).

Feulgen DNA image densitometry was conducted as a further control using the same two accessions (no. 10, four seedlings, 382 nuclei and no. 21, three seedlings, 380 nuclei) in flow-cytometric tests. Again the results indicated that the genome size of accession 10 was higher than accession 21. The 1.029-fold difference detected was smaller than the estimate made using flow

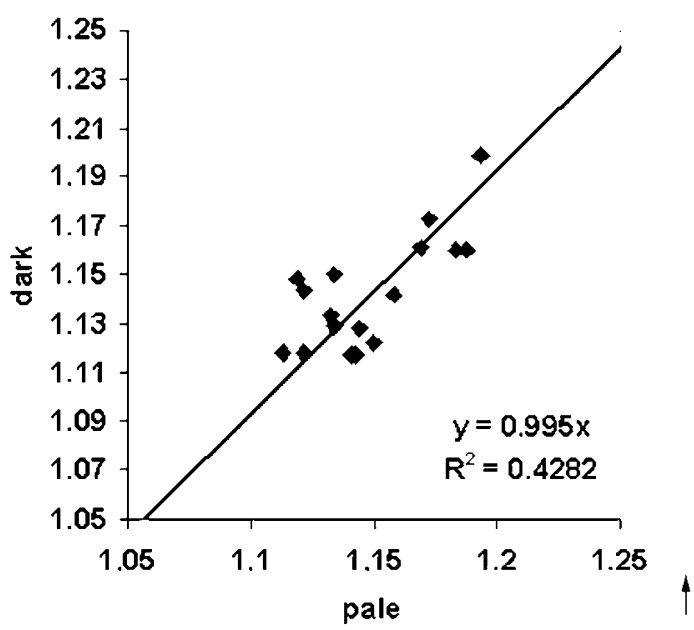

Figure 1 Correlation of genome sizes within accessions in plants from pale and dark caryopses of D. villosum (compare Table 2). The correlation is significant at $P<0.001$.

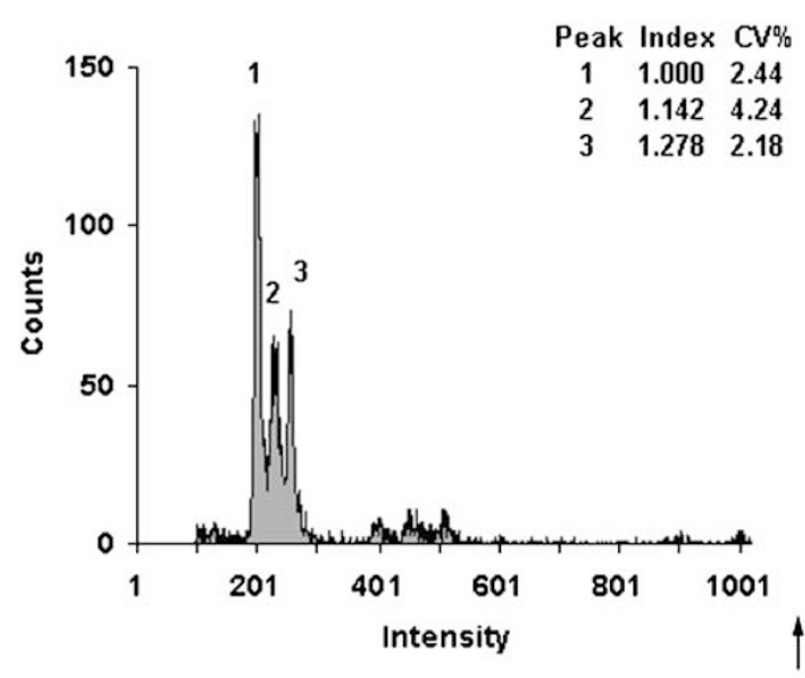

Figure 2 Flow-cytometric nuclear DNA histogram of coprocessed D. villosum plants from the accessions ranking very high (peak 3, GRA 992/88) and lowest (peak 2, GRA 1305/91), respectively, and of the internal standard P. sativum (peak 1). 
cytometry and, as the number of seedlings was low, it actually proved to be nonsignificant $(P=0.2961$, twosided $t$-test).

\section{Discussion}

The colour variation between caryopses of the same mother plant in D. villosum is based on developmental differences in maternal tissue. Whereas associated physiological differences between seedlings such as in germination vigour or dormancy could be easily comprehended, it is more difficult to understand how the DNA amount in the embryonic and seedling genome could be influenced. The previously reported genome size differences (Cremonini et al, 1994; Frediani et al, 1994), their development during germination (Frediani et al, 1994), and the associated changes in some repetitive DNA sequences (Frediani et al, 1994) clearly belong to the 'unorthodox' category of variation (Greilhuber, 1998). The 1.66-fold genome size variation within populations described by Caceres et al (1998) also appears implausible, because populations are interbreeding reproductive communities with continual genetic homogenization. Only unorthodox mechanisms could lead to such extreme variation (n.b. D. villosum populations are diploid and no B-chromosomes have been described).

From our data it seems clear that reports of such genome size differences between plants derived from differently coloured caryopses must be treated with utmost caution. The moderate variation between populations on a wide geographical scale detected in the present investigation is more or less within the range of the variation which seems to exist in many species (compare Lysák and Doležel, 1998; Suda et al, 2003). The variation between individuals of the same population is mostly small, and for methodological reasons must be treated cautiously. Secondary metabolites such as phenolics, first described by Greilhuber (1987) as staining inhibitors in Feulgen densitometry, are now considered to be possible explanations for inconsistent results in flow cytometry (Noirot et al, 2000; Price et al, 2000). Intraspecific variation in genome size must therefore, be considered with due scepticism.

Caution is also in order regarding the method of quantitative DNA staining with the Feulgen reaction as adopted by Frediani et al (1994), Cremonini et al (1994), and Caceres et al (1998). In all of these studies, hot hydrolysis $\left(60^{\circ} \mathrm{C}\right)$ with $1 \mathrm{~N} \mathrm{HCl}$ was applied to enzymemacerated root tip squashes on glass slides. Hot hydrolysis treatment is now known to generate artifactual variation. This is due to the accelerated reaction kinetics for hydrolysis at $60^{\circ} \mathrm{C}$, so that there is insufficient time for obtaining the optimal stoichiometry of staining. For a longer 'plateau' of optimal staining, hydrolysis with $5 \mathrm{~N} \mathrm{HCl}$ at $20.0^{\circ} \mathrm{C}$ for $60 \mathrm{~min}$ is now recommended (see Greilhuber and Baranyi, 1999; Greilhuber and Temsch, 2001). Moreover, Greilhuber and Ebert (1994) found that enzyme-macerated slides, which are aged before hydrolysis and staining, give erratic results. The methods used by Frediani et al (1994), Cremonini et al (1994), and Caceres et al (1998) may, therefore, be sufficient to explain the 'plastic data' on genome size in D. villosum.
Over the years there has remained little support for the once strongly advocated idea of the plastic genome, as criticized by Greilhuber $(1988,1998,2005)$, in reports on conifers, Sambucus, Hedera helix, Scilla siberica, and P. satioum. Certain other reports on genome size plasticity may also be compromised, because they come from the same source and can be assumed to be based on the same technical and theoretical premises. The particular developmental genomic changes in sunflower as described by Natali et al (1993) and the direct responses of Festuca arundinacea to temperature changes by redundancy modulation of interspersed DNA repeats (Ceccarelli et al, 2002) also belong to this category. In sunflower, Price et al (2000) described endogenous staining inhibitors (probably of phenolic nature) and their role in producing false estimates of DNA content variation (even with flow cytometry), which is comparable to the action of phenolics in Feulgen densitometry as described by Greilhuber (1987). Flax, Linum usitatissimum, and its 'genotrophs' assume a special position in the list of plants with records of having plastic genome. Flax represents the first, best-studied and probably mostaccepted case of environmentally induced, heritable, and cytophotometrically measurable genome size variation (Evans et al, 1966; Cullis, 2005, and the literature therein). Notwithstanding the molecular evidence for flax 'genotrophs', genome size differences have twice been questioned, based on cytometric observations, that is, by Schweizer (1980) and by Greilhuber (1998). Constant genome size was found over the L (large), S (small), and $\mathrm{Pl}$ (plastic) genotrophs, whereas previous reports indicated that $S$ and $L$ should have differed about 1.16-fold.

These caveats are not meant as supporting a rigid dogma of strict DNA constancy, which would preclude evolutionary changes in genome size altogether. In particular, the role of transposable elements for genome inflation, and deletion mechanisms for reduction are increasingly better understood (Bennetzen et al, 2005; Cavalier-Smith, 2005). However, the concept of the 'plastic genome' as proposed by Cremonini et al (1994) essentially assumes rapid, programmed, and conspicuous genome size changes. In $D$. villosum, the proposed changes are in the range of $1000 \mathrm{Mbp}$ per haploid genome, which are supposed to be reversible from one generation to the next. This kind of plasticity, which increasingly lacks support, should not be confused with high mutability and elicited transposon activity. These processes are now thought to be a reaction to genomic stress following hybridization and/or polyploidization (Wendel, 2000; Bennett, 2004; Leitch and Bennett, 2004; Bennett and Leitch, 2005a, b; Bennetzen et al, 2005).

\section{Acknowledgements}

We thank Professor Dr MD Bennett (Royal Botanic Gardens, Kew) for providing the facilities to conduct the final control measurements for this study. The work was supported by the Austrian Science Fund, research grant P14607-B03.

\section{References}

Bennett MD (2004). Perspectives on polyploidy in plants ancient and neo. Bot J Linn Soc 82: 411-423. 
Bennett MD, Leitch IJ (1995). Nuclear DNA amounts in angiosperms. Ann Bot 76: 113-176.

Bennett MD, Leitch IJ (2005a). Genome size evolution in plants. In: Gregory TR (ed) The Evolution of the Genome. Elsevier Academic Press: Amsterdam, Oxford, San Francisco. pp 89-162.

Bennett MD, Leitch IJ (2005b). Nuclear DNA amounts in angiosperms: progress, problems and prospects. Ann Bot 95: 45-90.

Bennett MD, Smith JB (1976). Nuclear DNA amounts in angiosperms. Philos Trans $R$ Soc Lond B 274: 227-274.

Bennetzen JL, Ma J, Devos KM (2005). Mechanisms of recent genome size variation in flowering plants. Ann Bot 95: 127-132.

Caceres ME, De Pace C, Scarascia Mugnozza GT, Kotsonis P, Ceccarelli M, Cionini PG (1998). Genome size variations within Dasypyrum villosum: correlations with chromosomal traits, environmental factors and plant phenotypic characteristics and behaviour in reproduction. Theor Appl Genet 96: 559-567.

Cavalier-Smith T (2005). Economy, speed and size matter: evolutionary forces driving nuclear genome miniaturization and expansion. Ann Bot 95: 147-175.

Ceccarelli M, Esposto M, Roscini C, Sarri V, Frediani M, Gelati M et al (2002). Genome plasticity in Festuca arundinacea: direct response to temperature changes by redundancy modulation of interspersed DNA repeats. Theor Appl Genet 104: 901-907.

Cremonini R, Colonna N, Stefani A, Galasso I, Pignone D (1994). Nuclear DNA content, chromatin organization and chromosome banding in brown and yellow seeds of Dasypyrum villosum (L.) P. Candargy. Heredity 72: 365-373.

Cremonini R. (1996). Cytological studies on Dasypyrum villosum http://genetics.bdtf.hu/Htmls/Publicat/hay1.html (accessed 17 Aug 2004).

Cullis CA (2005). Mechanisms and control of rapid genomic changes in flax. Ann Bot 95: 201-206.

De Gara L, Paciolla C, Liso R, Stefani A, Arrigoni O (1991). Correlation between ascorbate peroxidase activity and some anomalies of seedlings from aged caryopses of Dasypyrum villosum (L.) Borb. I Plant Physiol 137: 697-700.

Doležel J, Bartoš J, Voglmayr H, Greilhuber J (2003). Nuclear DNA content and genome size of trout and human. Cytometry 51A: 127-128.

Doležel J, Greilhuber J, Lucretti S, Meister A, Lysák MA, Nardi L et al (1998). Plant genome size estimation by flow cytometry: inter-laboratory comparison. Ann Bot 82(Suppl A): $17-26$

Evans GM, Durrant A, Rees H (1966). Associated nuclear changes in the induction of flax genotrophs. Nature 212: 697-699.

Frediani M, Colonna N, Cremonini R, De Pace C, Delre V, Caccia $R$ et al (1994). Redundancy modulation of nuclear DNA sequences in Dasypyrum villosum. Theor Appl Genet 88: 167-174.
Greilhuber J (1987). 'Self-tanning' - a new and important source of stoichiometric error in cytophotometric determination of nuclear DNA content in plants. Plant Syst Evol 158: 87-96.

Greilhuber J (1988). Critical reassessment of DNA content variation in plants. In: Brandham PE (ed) Kew Chromosome Conference III. London: HMSO. pp 39-50.

Greilhuber J (1998). Intraspecific variation in genome size: a critical reassessment. Ann Bot 82(Suppl A): 27-35.

Greilhuber J (2005). Intraspecific variation in genome size in angiosperms: identifying its existence. Ann Bot 95: 91-98.

Greilhuber J, Baranyi M (1999). Feulgen densitometry: importance of a stringent hydrolysis regime. Plant Biol 1: 538-540.

Greilhuber J, Ebert I (1994). Genome size variation in Pisum sativum. Genome 37: 646-655.

Greilhuber J, Temsch EM (2001). Feulgen densitometry: some observations relevant to best practice in quantitative nuclear DNA content determination. Acta Bot Croat 60: 285-298.

Innocenti AM, Bitonti MB (1980). Differente invecchiamento nelle cariossidi 'chiare' e 'scure' di Haynaldia villosa Schur. Uno studio citofotometrico nei meristemi radicali quiescenti. Giorn Bot Ital 114: 29-35.

Innocenti AM, Bitonti MB (1983). Different duration of the mitotic cycle in seedlings from brown and black caryopses of Haynaldia villosa Schur. Caryologia 36: 27-32.

Leitch IJ, Bennett MD (2004). Genome downsizing in polyploid plants. Biol J Linn Soc 82: 651-663.

Lysák MA, Doležel J (1998). Estimation of nuclear DNA content in Sesleria (Poaceae). Caryologia 51: 123-132.

Natali L, Cavallini A, Cionini G, Sassoli O, Cionini PG, Durante M (1993). Nuclear DNA changes within Helianthus annuus L. changes within single progenies and their relationships with plant development. Theor Appl Genet 85: 506-512.

Noirot M, Barre P, Louarn J, Duperray C, Hamon S (2000). Nucleus-cytosol interactions - a source of stoichiometric error in flow cytometric estimation of nuclear DNA content in plants. Ann Bot 86: 309-316.

Obermayer R, Greilhuber J (1999). Genome size in Chinese soybean accessions - stable or variable? Ann Bot 84: 259-262.

Onnis A (1967). La dormienza nelle cariossidi di Haynaldia villosa Schur. in relazione allo stadio di maturazione. Giorn Bot Ital 101: 135-137.

Price HJ, Hodnett G, Johnston IS (2000). Sunflower (Helianthus annuus) leaves contain compounds that reduce nuclear propidium iodide fluorescence. Ann Bot 86: 929-934.

Schweizer D (1980). Fluorescent chromosome banding in plants: applications, mechanisms, and implications for chromosome structure. In: Davies DR, Hopwood RA (eds) The Plant Genome. Proceedings of the Fourth John Innes Symposium, Norwich 1979. John Innes Charity: Norwich. pp 61-72.

Suda J, Kyncl T, Freiová R (2003). Nuclear DNA amounts in Macaronesian angiosperms. Ann Bot 92: 153-164.

Vilhar B, Greilhuber J, Dolenc Koce J, Temsch EM, Dermastia M (2001). Plant genome size measurement with DNA image cytometry. Ann Bot 87: 719-728.

Wendel JF (2000). Genome evolution in polyploids. Plant Mol Biol 42: 225-249. 